\title{
Negotiation Failure - Case Of Daimler-Chrysler
}

\author{
Kwesi Atta Sakyi \\ B.A. (Hons.) Ghana \\ MPA (summa cum laude) \\ (Head-Research) ZCAS University \\ Dedan Kimathi Road, Lusaka, Zambia
}

\begin{abstract}
Negotiations are inevitable in business and in every facet of life. Often parties to a negotiation come to the negotiating table with wrong assumptions, unrealistic expectations, and what academics label as blinded awareness and focus failure because they fail to realise the import of information which is made available and which can lead to negotiation success. Lack of listening properly and being magnanimous at the negotiation table causes negotiation failure. Negotiators often engage in stereotyping, resort to heightened emotions, and provocation of adversaries through bullying, armtwisting and logrolling and horse trading tactics. Often negotiators fail to take cognizance of contextual and extenuating circumstances because they seek selfish and parochial interests in a winner-take all, zero-sum scenario where they assume they are dealing with a fixed pie situation, and their axiomatic positions cannot be compromised. This essay on negotiation failure regarding the Daimler-Chrysler merger failure draws parallels from history and geo-politics, citing the Cold War era standoff, Shuttle diplomacy regarding the Strategic Arms Limitation Treaties (SALT), the Oil-forfood UN-Iraqi deal, and the Israeli-Palestinian imbroglio as typical negotiations some of which were successes and others failures. The author of this essay makes the assumption that negotiation is not a one-off process but a continuous work in progress of establishing long term rapport, good will, and building bridges of friendship and investment in long term binding bonds of mutual coexistence.
\end{abstract}

Key Words: negotiations, conflicts, mergers, merger failures, negotiation failures, conflict resolution, ADR, soft diplomacy, blinded awareness, focus failure

\section{INTRODUCTION}

Daimler Mercedes Benz was created in 1885 by Carl Benz (Daimler.com) and it was among the first cars invented alongside Ford, Renault, Dodge, and Chrysler. In this assignment on Negotiation Failure, the writer will first examine the background of the corporate merger between Daimler Benz of Germany, and Chrysler Motors of the USA, and examine why the merger failed, using the theoretical literature on conflict, negotiations and some aspects of international negotiation diplomacy as examples to illustrate points made.

Conflict is inevitable in life and the corporate world has a lot of conflicts, especially when two companies agree to merge, such mergers often fail or are not as successful as envisaged. Mergers are entered into with the hope that they will create synergies, economies of scale and economies of scope. Invariably, the evidence from research shows that post-merger results or performance are often below the pre-merger performance results of the merging companies. This has been explained as a result of cultural incompatibilities and also not doing enough due diligence before the merger was consummated. 


\section{LITERATURE REVIEW}

Kreitner \& Kinicki (2008:379) allude to the fact that many cross-border mergers, alliances, and joint ventures such as the Daimler-Chrysler merger do go awry despite the fact that in a globalised world, they are the norm and the way to go to stay in competition on the market.

Kreitner \& Kinicki (2008:379) also observe that cross border mergers do present huge conflicts. They cite the example that while Mexicans, Chinese, and Japanese do downplay conflict in public because of saving face, Westerners and particularly Americans do believe in public confrontations. They state that the Nuclear Arms Disarmament deals and negotiations involving the USA, China, Japan, and North Korea have failed in the past due to misperceptions, power play, mistrust, miscommunication of real intentions and motives, suspicion, pursuing narrow and selfish national interests, selfishness, being egocentric, and not being prepared to listen to the demands of the other parties because of having assumed entrenched and fixed pie positions.

The negotiators had often come to the negotiations wearing blinders and suffering from negotiation myopia, blinded awareness, and focus failure, because of prejudice, prejudgment, stereotyping and not prepared to negotiate in good faith because they think their adversaries should negotiate on their own terms, willy-nilly.

Kreitner \& Kinicki (2008:379) refer to negotiation failure as being put down to negotiators being dialectical or axiomatic or engaging in polemics and being fixated with ideological obsessions such as asking adversaries to imbibe their own beliefs and standards of free markets, participatory democracy, human rights, multi-party democracy, protecting the rights of women, children, ethnic minorities, and animals.

Be that as it may, such demands are based on morals and there are no one set of universal morals because of differences in religions, historical antecedents and geographical/geopolitical circumstances. Some demands at negotiations may look utopian while others may see them as leading to dystopia and antithesis of what they stand for.

Kreitner \& Kinicki (2008:384) believe that a holistic and integrative approach to conflict resolution is the best way to go without making anyone look like capitulating or being treated as a minor or underdog at the negotiating table. Kreitner et al. (2008) assert that some negotiations are doomed to failure where we have a conflict triangle with an outside third party invited to be a mediator or referee. Such third parties bring complications to negotiations as they also may pursue their own agendas.

During negotiations, the stance assumed by negotiators can be one of the following: avoiding some issues which are trivial, obliging with demands where obliging will win you plaudits and put you in the spotlight as a conciliator or peacemaker; trying to dominate others who have less power or resources or who look vulnerable through arm-twisting, bullying, threats, among others in a zero sum or win-lose approach scenario;

Capitulating may be done in the hope of being rewarded in a way; obliging; and seeking common ground through a win-win integrative approach. Nelson Mandela was a notable and foremost negotiator because he was patient, charismatic, a peacemaker, and he always sought the global interest of all the people in a negotiation (Shapiro.com)

Nikita Krushchev, the former Soviet leader during the Cold War (History.com) was known to be an implacable Communist but he was a Statesman and universalist as during the Bay of Pigs 
imbroglio between the former USSR and the USA in the nuclear stand-off, he showed good sense by withdrawing the nuclear bombs planted in Cuba, 90 miles from Florida or the USA mainland (Shapiro.com)

Kreitner et al.(2008) advise that some negotiations can be conducted low profile by seeking Alternative Dispute Resolution(ADR) or engaging in behind the scenes Shuttle Diplomacy such as the approach of the shrewd former USA Secretary of State, Henry Kissinger during several Strategic Arms Limitation Talks (SALT) with the former Soviet Union to stave off war during the Cold War period from 1945 to 1990 (break-up of the former Soviet Union under Sergei Gorbachev in Perestroika and Glasnost; and the fall of the Berlin Wall in 1989) Krushchev believed in Peaceful Coexistence, Detente, Entente, Continuous Dialogue, Ubuntu, and Nsaka which are African terminologies for Dialogue.

Winston Churchill once said that it is better to "jaw-jaw than to war-war", meaning that dialoguing over disputes is better than taking to arms. From a human needs theory, conflict resolution can be examined from the human needs theory (Kelman: 1990).

Kelman (1990: 284) posits that the solution to the protracted Israeli-Palestinian problem is for each of the parties to the conflict to be gracious, open-minded and receptive to the idea of embracing change, coexistence and overcoming the entrenched needs and fears that their very existence depends on the annihilation of the other party whose presence must not be recognised or tolerated. This is an extremist position of non-tolerance and it creates an ethical and existential problem, an affront to all the internal conventions and acceptable protocols, because no person in the world should be declared stateless.

Negotiation failure in the Middle East debacle is due to refusal of the negotiators to the conflict to have empathy, rationality, and realisation of their peculiar contextual geographical location, for them to climb down from their highly-perched positions of obduracy, contumacy, obstreperousness and intransigence or refusal to change or accept the realities on the ground. Israelis and Palestinians need to live side by side in order to live, and that it is a conjoined and mutually consanguineous relationship which cannot be undone in human temporal basis by the resort to coercion or threats or by war.

According to Kelman, solutions which address their basic needs and fears will be more lasting, satisfactory, and durable. Perhaps that solution lies with the current Millennials who know no boundaries on cyberspace. Kelman (1990:285) proposes a third party interactive approach of building bridges through informal group contacts and using such as leverage to thaw the ice by facilitating progress in stalemated or impasse negotiations. Through informal contacts through third party facilitators, grassroots people bypass the political leaders and get to talk and interact in creative ways to solve their differences (Kelman: 1990:296)

According to the human needs theories of Maslow and McCleland, people have needs for affiliation, power, achievement, growth, and recognition. Kreitner et al. (2008:388) describe conflict as a give and take process between two interdependent parties whose conflict resolution approaches can either be integrative approach (win-win) or distributive approach (zero sum or win-lose). The latter approach has been the one at stake in the Middle East.

According to Kreitner et al.(2008:389) the success of a negotiation depends on the quality and quantity of information made available to the negotiating parties and that insufficiency of data and information can lead to information asymmetry and incomplete contracts which in turn can lead to mistrust, and negotiation failure. 
Kreitner et al.(2008: 390) make the observation that the types of personalities also affect the outcome of negotiations. Mandela, Kissinger, Churchill, Theodore Roosevelt, and Krushchev were great negotiators in their time due to their magnetic and infectious personalities which reflected trust, willingness to attend to issues objectively and holistically, and their foresight and statesmanship bordering on brinkmanship, belief in universal good and the somum bonum or pro bono publicio (cf. John Stuart Mills, Jeremy Bentham, John Locke, Montesquieu, Thomas Paine, Thomas Hobbes, J.J. Rousseau, Pareto, Baumol, among others)

The two sides to a negotiation should address their basic needs and fears as well as their identities, however, not on polemical grounds of ideology or religion but on the neutral grounds of the greater good for the greater number premised on the tenets of the Universal Declaration of Human Rights as declared in 1948 by the UN with regard to right to life, liberty, property, freedom of association, freedom of conscience, freedom of movement, and freedom to the inalienable larger freedoms to work, health facilities, education and residence.

According to Kretner et al.(390:390) negotiation research establishes the point that women tend to reach compromise or settlement faster than male negotiators. This informs this discussion that the world would be a better world with more engagement of females in negotiations to avoid negotiation failures.

This portends that women are by nature integrative while men are fragmental as they tend to pursue distributive solutions or winner-takes-all approaches. Kreitner et al.(2008:391) advise that to avoid negotiation failure, the parties to a negotiation should avoid puffery, deception, weakening opponents, self-centredness, resistance to change, non-disclosure of pertinent information, distraction, information overload, and exploitation of weaker opponents.

\section{DISCUSSION}

Johnson (n.d.:24) in his book, Mergers and Acquisitions, advises that before any merger, the parties involved should do due diligence on each other by researching on each other's profile pertaining to partner performance results, history, attractiveness as a partner, costs profile or structure, its cultural congruence or otherwise (cultural mismatch or incompatibility) suitability as a partner, feasibility, reputation, market share, technologically savvy, financial strength, ownership and legal structure, and nature of its products.

The literature on why the DaimlerChrysler merger failed in the early period, 2000-2001 attest to these factors outlined above as despite the merger being touted as a merger of equals, Daimler did not see it as such as it dominated the show and marginalised Chrysler. Hollmann et al. (2010) posit that the merger failed on the grounds of cultural mismatch between American and German cultures.

Hollmann et al. hold the view that both the corporate cultures of Daimler and Chrysler were deeply embedded in their respective national cultures which showed deeply contrasting styles to management and leadership, and as such the failure of the merger was somehow more political than institutional or corporate. Germans are said to have a mechanical and rigid approach whereby everything is structured in Max Weber's inflexible Bureaucracy. Germans are risk-averse, and they are not as individualistic and competitive as Americans who are creative, flexible, freewheeling, independent thinkers, and results and efficiency oriented.

While Germans root for long term results, Americans want short term gains or results (Hollmann et al.) Hollmann states that the USA or America is an immigrant country with much diversity and a melting pot of cultures. It is also a country with a history of adventure of 
expansion to the West or expanding frontier mentality of conquest, triumph, and survival instinct. Above all, the people in the USA come from a background of Protestant ethics of industry, profit-making, and creativity.

Germans on the other hand have a homogenous society, inward looking, somehow collectivist, state-mindful or patriotic, proud, and also with longer power distance or belief in authority and tall hierarchies (cf. Hofstede)

Americans, in contrast, believe in being free-born and have belief in shorter power distance, and they have a pragmatist approach to problem-solving because they believe in larger freedoms, equality, and spirit of adventure (Hollmann et al.) According to Hollmann et al., the merger of Daimler and Chrysler occurred during the watch of Robert Eaton as CEO at Chrysler and Jurgen Schrempp at Daimler. Schrempp manoeuvred and manipulated the merger such that he made the Germans dominate by populating the top hierarchy with Germans. Prior to the merger, many American employees had quit, and by 2001, Chrysler had made a loss of 521 million dollars (Hollmann et al.) (Weber, 2003:400-415) Had Chrysler done their homework well, they would not have fallen head over heels for the merger.

Daimler was known as a global brand of excellence and reliability while Chrysler was famous for their creativity and innovative products. Synergy, market sharing, and economies of scale and scope were some of the benefits perceived for the merger but it was not to be as the Germans saw the relationship as a power struggle for cultural dominance and a zero sum deal. It proved clear in the unfolding early years that the merger of equals had turned foul into a game of champion remains standing tall, the loser slumps to his fall on the floor looking small. What was to be was not, dashing all hopes of stockbrokers and stockholders on the American side.

Deresky (2000:174) states that Arabs use the Affective appeal or emotions when negotiating while Russians base their negotiations on Axiomatic or Ideological positions and positions of power. He further observes that North Americans enter negotiations on the basis of observing Rationality and using facts and figures as basis for arguments. Japanese, Chinese, and other East Asians want a long term relationship established between them and their negotiators, and this Asian model was used to advantage by Mandela with the Boer Apartheid government, by Kissinger in his Camp David Accord, by Krushchev in the 1961 Bay of Pigs mishap with the USA under the Cold War with John Fitzgerald Kennedy as US President.

They all built personal friendships and bonds with their adversaries. That was what should have happened in the DaimlerChrysler merger. The late former UN Secretary General, Kofi Annan, used soft diplomacy, patience, personal charm, a listening ear, tolerance, and above all personal charm to win over Saddam Hussein during the stand-off in the Weapons of Mass Destruction debacle and the UN-Iraqi Oil for Food Deal (CNN.com)

Deresky advises that for a successful negotiation, prospective negotiators should go through four stages namely, pre-negotiation preparation, relationship building, exchange of taskrelated information, and finally using persuasion at the negotiating table (Deresky, 2000:176178) Had Daimler and Chrysler gone through these steps, perhaps some pitfalls could have been avoided.

Deresky (2000:176-178) also points out that there are Low context and High context cultures which should be identified, analysed, and addressed appropriately during negotiations. For 
example, in Low context cultures, emotions are suppressed while in High context cultures, emotions are expressed freely.

Arabs, Africans and Asians have high context cultures, though not much of Asians as of the Arabs and Africans. Rue et al. (2007) opine that successful negotiations deal with problems and not people, they do not pull surprises, are transparent, premised on goodwill, no ill-will to damage the adversary, engages in review of issues at stake, maximizes the pie for all, and above all, looks for common and mutual grounds of agreement as basis for making progress.

Successful negotiations avoid confrontation and attempts to smoothen or cover up burning issues (Rue, 2007:335-360) Martin (2009:697-699) also advises that parties to a negotiation should look at interests at stake and not positions or stands taken by the negotiators because entrenched positions are axiomatic and non-negotiable while interests are universal as they address human needs and fears.

Martin (2009) calls for creativity to explore innovations for achieving gains which benefit all or at least benefit at least one person and makes nobody worse off by at least maintaining the status quo ante. Negotiators should be prepared to make sacrifices to have gains with no resort to horse-trading or logrolling in a spirit of quid pro quo (nothing goes for nothing). Horsetrading and logrolling are corrupt and may lead to short term selfish gratification and long term collective problems.

Huthwaite (cited in Martins, 2009:699) states that negotiations fail when negotiators resort to blame game, bad mouthing, name calling, confrontations, assuming defensive and attacking positions, proving your assertiveness, and engaging in a spiral of proposals, counter-proposals, ad nausea ad infinitum.

Negotiators should not engage in a fight or flee scenario, unnecessary competition but they should be reasonable enough to engage in collaborative efforts, compromises, interactive activities, sometimes accommodation, and in a worst case scenario, the use of coercion. One should not always assert one's own way as one should be reasonable enough to listen to the other party (audi alterem partem)

Weber \& Camerer (2003:400-401) in the post-mortem of the DaimlerChrysler merger, did conclude that the merger was rushed and not much groundwork and homework was done before entering into the merger, hence the cultural mismatch, and the perceived match of corporate equals was not to be as it turned out to be an incompatible relationship with the Germans calling the shots. At best, it could have been a Strategic Partnership but not a merger. The global contextual factors as well as country-specific factors were not conducive for the merger. In the first place, the Asian markets continue to make technological gains and produce far cheaper products compared to the USA or Germany on account of highly skilled but cheaper labour. They also have the market critical mass as well as rapid GDP growth. The PESTEL model should have been applied robustly in reviewing the merger.

Post-merger performance of the merged Company according to CNN.com (February 26th, and $29^{\text {th }} 2001$ ) was far lower than the pre-merger performance because key American employees had left and investor confidence had sunk low. The merger was like mixing water and oil or mixing iron and clay. In the USA, Chrysler which was incorporated in 1922 was the third largest automobile Company after General Motors and Ford Corporation (Chrysler.com) 


\section{RECOMMENDATIONS FOR NEGOTIATION SUCCESS}

- Negotiators should look at interests not positions

- Mergers should be subject to thorough scrutiny on the basis of Michael Porter's criteria of Suitability, Feasibility, and Attractiveness (SFA Criteria)

- Merger should concentrate on problems to solve and not people

- Negotiators should look at the bigger picture by rising above the problems and adopt the helicopter factor by seeing issues from a systems perspective whereby the dots are connected to the parts because a system is a whole and not a mere collection or sum of its constituent parts

- Cultural imperatives should be factored in and given greater weight than all factors

- Enduring understanding and insight can be gained in negotiations if negotiators get to know one another on a personal level like Mandela, Kennedy, Krushchev, Kissenger, Annan, and other great negotiators in history did

- Agreements and deals reached should be taken in their entirety, to include the spirit and letter of the agreements to avoid negotiation failure

- Negotiations should be conducted in good faith with no hidden agenda, sabre rattling, threats, and logrolling

- Shuttle diplomacy, Quiet behind-the- scenes diplomacy, and subtle negotiations should be conducted for the greater good (cf. History.com; CNN.com)

- Even after a deal is cut, the process of negotiation should be on-going in an informal manner to consolidate it through building of personal bonds and bridges

\section{CONCLUSION}

The corporate negotiation failure of the DaimlerChrysler merger which a few years down the line led to a break-up or demerger was said to have been greatly due to cultural mismatch or incompatibility as a result of the national cultures of the USA and Germany being in sharp contrast to each other. The euphoria of an utopian merger fizzled into a classic dystopia and abysmal negotiation failure because the negotiators did not do due diligence and if they did, they should have properly assessed the cultural imperatives well by checking the works of authorities in cross border cultures such as Geert Hofstede, Fons Trompenaars, Robert House, Guest, Adler, Ingelhart, Deresky, the GLOBE Study, and Thomas \& Parkinson, among many others.

\section{References}

Britannica.com (n.d.) Chrysler American Company [Online] Retrieved from https://www.britannica.com/topic/Chrysler

CNN.com (1998) Annan Heads Back to UN with Iraqi Deal [Online] Retrieved from http://edition.cnn.com/WORLD/9802/23/iraq.1/

Daimler.com (n.d.) Daimler Company History [Online] Retrieved from https://www.daimler.com/company/tradition/company-history/1885-1886.html

Deresky, H. (2000) Management- Managing Across Borders and Cultures (3rd ed.) New York, N.Y.: Prentice Hall, Upper Saddle River

History.com (n.d.) Nikita Khrushchev [Online] Retrieved from https://www.history.com/topics/cold-war/nikita-sergeyevich-khrushchev

Hollmann, J., de Moura Carpes, A., \& Beuron, T.A. (2009) The DaimlerChrysler Merger- A Cultural Mismatch [Online] Retrieved from https://periodicos.ufsm.br/reaufsm/article/viewFile/2506/1536

Johnson, J. (2009) Mergers and Acquisitions London: Prentice Hall

Kelman, H.C. (1990) Applying a Human Needs Perspective to the Practice of Conflict

Resolution-The Israeli-Palestinian Case cited in Burton, J. (1990) (Reader) Conflict: Human Needs Theory New York, N.Y.: St Martin Press 
Kreitner, R. \& Kinicki, A. (2008) Organisational Behaviour (8th ed.) New York, N.Y.: McGraw Hill

Martin, J. (2009) Organisational Behaviour and Management (3rded.)

Rue, L.W. \& Byars, L.I. (2007) Management Skills and Applications (13 ${ }^{\text {th }}$ ed.) New York,

N.Y.: McGraw Hill Irwin3 of the best negotiators in history ShapiroNegotiations.com (n.d.) 3 of the Best Negotiators in History [Online] Retrieved from https://www.shapironegotiations.com/3-best-negotiatorshistory/

Weber, R. A. \& Camerer, C.F. (2003) Cultural Conflict and Merger Failure: An Experimental Approach [Online] in Management Science Vol. 49 No. 4 pp. 400-415 4th April 2003 Retrieved from http://www.its.caltech.edu/ camerer/mgtsci03.pdf 